\title{
ROLE OF STIGMATIC FLUID IN OVARY GROWTH AND SENESCENCE OF POLLINATED DENDROBIUM FLOWERS
}

\author{
APINYA WISUTTIAMONKUL ${ }^{1}$ and SAICHOL KETSA ${ }^{2,3, *}$ \\ ${ }^{1}$ Agricultural Technology Department, Thailand Institute of Scientific and Technological Research, Amphoe Khlong Luang \\ Pathum Thani 12120, Thailand \\ ${ }^{2}$ Department of Horticulture, Faculty of Agriculture, Kasetsart University, Chatuchak, Bangkok 10900, Thailand \\ ${ }^{3}$ Academy of Science, The Royal Institute, Dusit, Bangkok 10300, Thailand \\ * Corresponding author: agrsck@ku.ac.th
}

\begin{abstract}
Pollination induced an increase in ethylene production concomitantly with ovary growth, epinasty, drooping, changes in venation and fading of the colour of the flowers of Dendrobium 'Pompadour'. Removal of stigmatic fluid prior to pollination significantly reduced ovary growth, while ethylene production, epinasty, drooping, venation and colour of pollinated flowers were not significantly affected. Removal of stigma fluid had no effect on ovary growth of non-pollinated flowers treated with 1-aminocyclopropane-1-carboxylic acid (ACC), but significantly reduced the ovary growth of non-pollinated flowers induced by the application of napthaleneacetic acid (NAA). The effect of stigmatic fluid on ovary growth of pollinated flowers is discussed.
\end{abstract}

Keywords: stigmatic fluid, ethylene production, ovary growth, senescence

\section{Introduction}

Many flowers show early petal senescence after pollination (O'Neill 1997; O'Neill and Nadeau 1997). In the case of the flowers of the orchid Dendrobium, non-pollinated flowers senesce after up to 3-4 weeks, whereas pollination is rapidly followed by visible symptoms of senescence (Ketsa and Rugkong 1999). The direct cause of Dendrobium flower senescence following pollination is the pollination-induced increase in ethylene production (Ketsa and Luangsuwalai 1996; Ketsa and Rugkong 2000a; Ketsa et al. 2001). Pollination induces a syndrome of developmental events that includes epinasty of the flower stalk, flower pigmentation and growth of the ovary (Ketsa and Rugkong 2000a; Ketsa and Rugkong 2000b; Ketsa et al. 2001).

The stigma in many species exudes an aqueous substance. This stigmatic fluid consists of water, sugars, fatty acids and amino acids (Konar and Linskens 1966; Martin 1973; Lovell et al. 1987; Lack and Diaz 1991). This fluid seems to aid the adherence of pollen to the stigma and to promote both pollen germination and pollen tube growth. Konar and Linskens (1966) also report that this fluid is important for ovary growth.

The present study investigates the role of stigmatic fluid in post pollination development, including ovary growth, of Dendrobium flowers. It is suggested that the increase in ethylene production and several other early post pollination changes in orchids, are due to the presence of ACC (the direct precursor of ethylene) and auxin-like compounds in pollinia (O’Neill 1997; Porat et al. 1998). In this study we investigated the effects of applying ACC and an auxin (NAA) to the stigma of non-pollinated flowers from which the stigma fluid was removed.

\section{Materials and methods}

Inflorescences of Dendrobium 'Pompadour' were purchased from a commercial grower near Bangkok. They consisted of five to seven open florets and five or six flower buds. Inflorescences were harvested in the morning and brought to the laboratory within $2 \mathrm{~h}$ of harvest. The upper part of the stem of the inflorescence with attached buds was removed and only the first five open florets were used. The stem at the base of the inflorescence was cut at an angle, $12 \mathrm{~cm}$ from the first open floret and the cut end inserted into a $15-\mathrm{ml}$ centrifuge tube containing $10 \mathrm{ml}$ of distilled water. Inflorescences were kept at ambient temperature $\left(29.5 \pm 2{ }^{\circ} \mathrm{C}\right)$ and relative humidity $(76 \pm 3 \% \mathrm{RH})$, and under natural light conditions.

Flowers were cross-pollinated by placing the pollinia from other open florets of Dendrobium 'Pompadour'. Prior to pollination or treatment with chemicals the stigmatic fluid was gently removed from open florets, using a small metal scoop specially made for this experiment.

1-Aminocyclopropane-1-cyclopropane acid (ACC) (20 nmol per floret) or napthaleneacetic acid (NAA) $(20 \mu \mathrm{g}$ per floret) was applied in distilled water to the stigma surface of non-pollinated flowers, with and without stigma fluid. The same volume of distilled water was applied to the stigma surface as a control.

The ovary diameter was determined at the proximal end, using a calliper. Orchid flowers exhibited peduncle epinasty after pollination, which was measured in terms of the distance between the lip and pedicel (Ketsa and Rugkong 1999). The time to epinasty, drooping, venation and colour fading of individual open florets was recorded daily. 

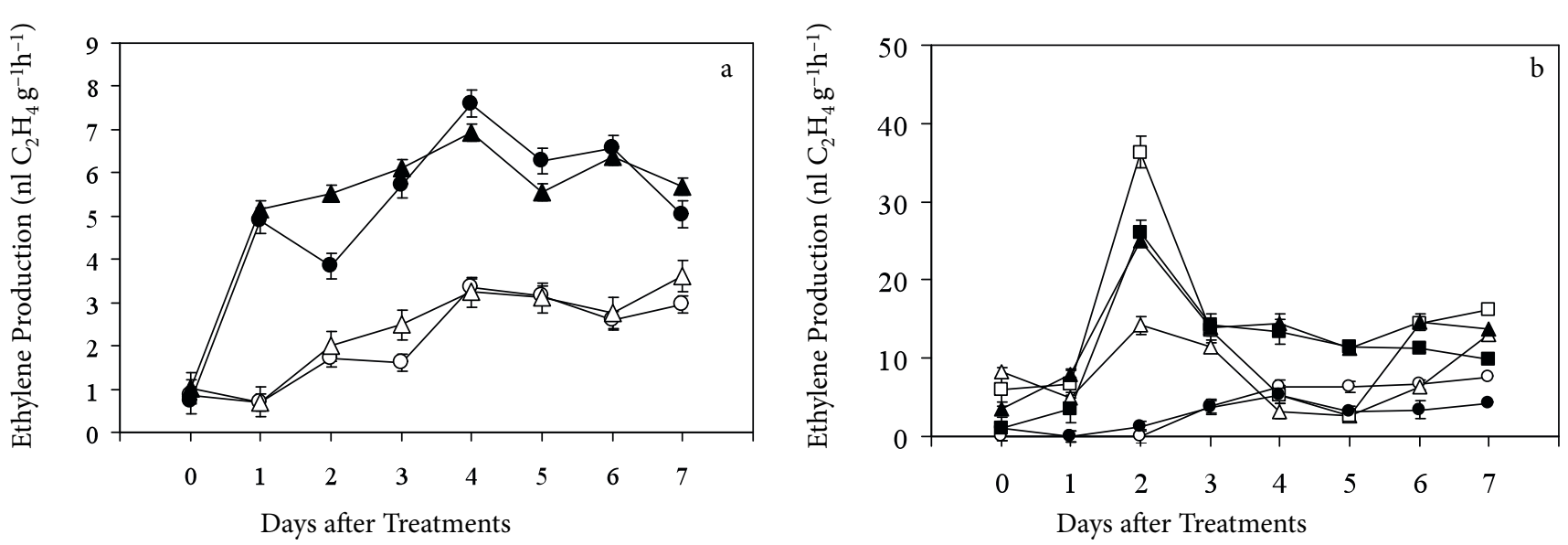

Fig. 1 Production of ethylene by flowers: (a) ethylene production of non-pollinated $(\circ, \Delta)$ and pollinated $(\bullet, \boldsymbol{\Delta})$ flowers with $(\circ, \bullet)$ and without $(\Delta, \boldsymbol{\Delta})$ stigmatic fluid; (b) ethylene production of non-pollinated flowers with $(0, \Delta, \square)$ and without $(\bullet, \boldsymbol{\Lambda}, \boldsymbol{\square})$ stigmatic fluid and treated with distilled water $(\circ, \bullet), \operatorname{NAA}(\square, \boldsymbol{\square})$ or ACC $(\Delta, \boldsymbol{\Delta})$. Values are means for 25 open florets $\pm \mathrm{SE}$.

Individual inflorescences were weighed and placed in airtight, 4 litres glass bottles with gas sampling ports. At various intervals, bottles were sealed for $2 \mathrm{~h}$ and samples of $1 \mathrm{ml}$ gas were withdrawn from the headspace for ethylene determination using a gas chromatograph equipped with a flame ionization detector (Shimadzu, Kyoto, Japan). After each determination, the bottles were opened for aeration. There were 10 replicates of each treatment.

Five inflorescences were used in each treatment and each inflorescence bore five open florets. Where possible, means were compared using Duncan's new multiple range test (DMRT). The experiments were repeated at alater date.

\section{Results}

Ethylene production by non-pollinated flowers with and without stigmatic fluid steadily increased during the period of the study. Ethylene production of pollinated flowers increased much more rapidly (Fig. 1a). Removal of stigmatic fluid had no significant effect on ethylene production of flowers, either non-pollinated or pollinated (data not shown).

Application of NAA or ACC to the stigma resulted in an increase in the production of ethylene, which peaked on day 2 (Fig. 1b). Treatment with NAA resulted in a higher production of ethylene than that with ACC. On day 2 the production of ethylene by NAA-treated flowers with stigmatic fluid was greater than that of NAA-treated flowers without stigmatic fluid. The opposite was recorded when treated with ACC (Fig. 1b).

The ovaries of non-pollinated flowers with and without stigmatic fluid did not grow, whereas those of similarly treated pollinated flowers steadily grew throughout the period of the study. Ovary growth of pollinated flowers with stigmatic fluid increased more rapidly than that of flowers from which the fluid was removed (Fig. 2a). This difference in the rate of growth was statistically significant at the end of the study period, (Table 1).

Ovary growth of NAA-treated non-pollinated flowers with and without stigmatic fluid rapidly increased throughout the study period. This growth was greater in flowers with stigmatic fluid (Fig. 2b; Table 2). The ovaries of ACC-treated flowers with and without stigmatic fluid did not increase in size (Fig. 2b).

Epinasty of the flower pedicel is here shown to result from a decrease in the distance between the lip and peduncle that occurs within $0-2$ days of pollination (Fig. 3a). The later change (increase in distance) is due to the inward folding (called drooping) of the petals, in-

Table 1 Size of the ovaries of flowers of Dendrobium 'Pompadour' from which, before pollination, the stigmatic fluid was either removed or not removed.

\begin{tabular}{|l|c|c|}
\hline \multicolumn{1}{|c|}{ Treatment } & \multicolumn{2}{c|}{ Ovary size $(\mathbf{m m})^{1}$} \\
\cline { 2 - 3 } & Day 0 & Day 7 \\
\hline Non-pollinated flowers from which the stigmatic fluid was not removed & 2.72 & $2.71 \mathrm{c}$ \\
\hline Non-pollinated flowers from which the stigmatic fluid was removed & 2.79 & $2.74 \mathrm{c}$ \\
\hline Pollinated flowers from which the stigmatic fluid was not removed & 2.86 & $3.87 \mathrm{a}$ \\
\hline Pollinated flowers from which the stigmatic fluid was removed & 2.84 & $3.49 \mathrm{~b}$ \\
\hline F-test & $\mathrm{ns}$ & $* *$ \\
\hline
\end{tabular}

${ }^{1}$ Means within a column not sharing common letter are significantly different at $P=0.01$ based on DMRT; ns $=$ not significant, ${ }^{* *}=$ significant at $P=0.01$ and $n=25$. 

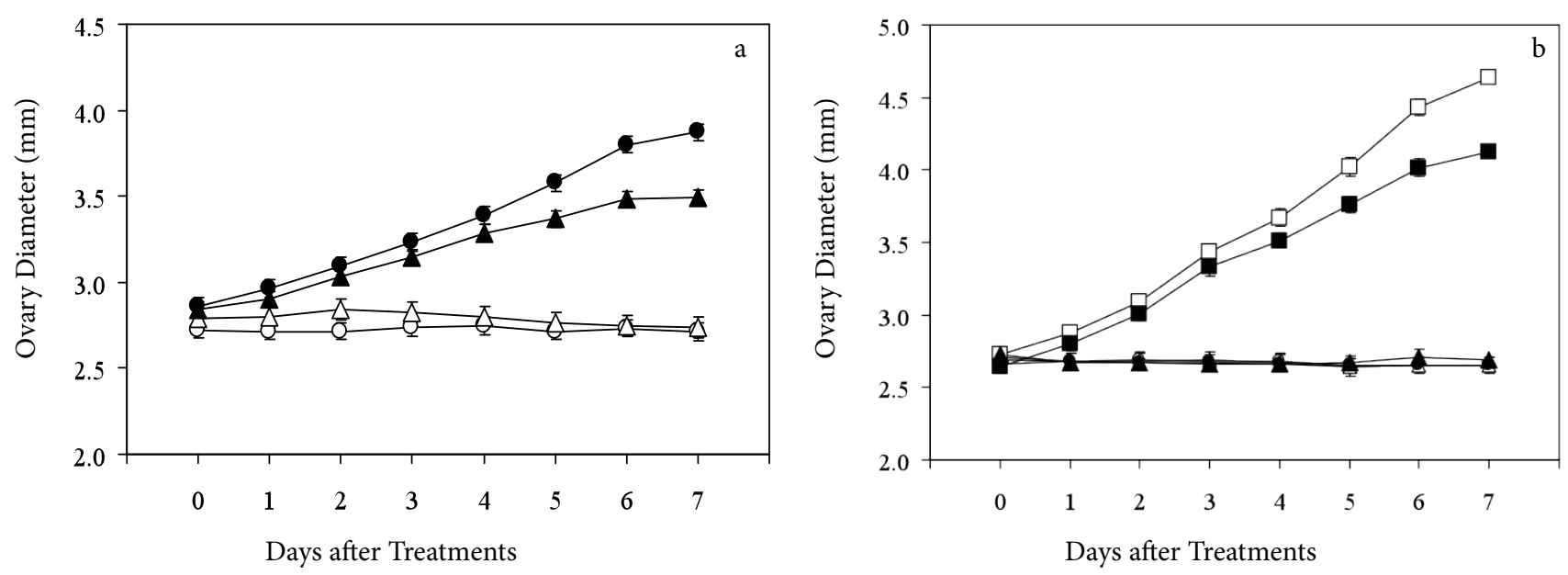

Fig. 2 Ovary growth of: (a) non-pollinated $(0, \Delta)$ and pollinated $(\bullet, \boldsymbol{\Delta})$ flowers with $(0, \bullet)$ and without $(\Delta, \boldsymbol{\Delta})$ stigmatic fluid; (b) non-pollinated flowers with $(\circ, \Delta, \square)$ and without $(\bullet, \boldsymbol{\Lambda}, \square)$ stigmatic fluid and treated with either distilled water $(\circ, \bullet), \operatorname{NAA}(\square, \boldsymbol{\square})$ and $A C C(\Delta, \boldsymbol{\Delta})$. Values are means for 25 open florets \pm SE.

cluding the lip. Epinasty did not occur in non-pollinated flowers, whether the stigmatic fluid was removed or not. Epinasty only occurred in pollinated flowers (Fig. 3a). The effect of removing stigmatic fluid on epinasty was not significant (Table 3).

Treatment of non-pollinated flowers with NAA resulted in epinasty similar to that recorded after pollination. Treatment of non-pollinated flowers with ACC resulted in slight epinasty (Fig. 3b). The presence of stigmatic flu- id did not have a consistent effect, but the effect of ACC did seem to be greater when stigmatic fluid was present (Fig. 3b).

The petals of pollinated flowers folded inwards, which is indicated by the change in the distance between the lip and peduncle that occurred 3-7 days after pollination (Fig. 3). Drooping was more marked in the presence of stigmatic fluid (Fig. 3a). Treatment of non-pollinated flowers with NAA also resulted in drooping, but there

Table 2 Size of the ovaries of Dendrobium 'Pompadour' flowers from which the stigmatic fluid was either removed or not and the stigma then either not treated or treated with distilled water, NAA or ACC.

\begin{tabular}{|l|c|c|}
\hline \multicolumn{1}{|c|}{ Treatment } & Day 0 & Ovary size $(\mathbf{m m})^{1}$ \\
\cline { 2 - 3 } & 2.69 & Day 7 \\
\hline Distilled water with stigmatic fluid present & 2.71 & $2.66 \mathrm{C}$ \\
\hline $20 \mathrm{nmol}$ ACC with stigmatic fluid removed & 2.72 & $2.65 \mathrm{C}$ \\
\hline $20 \mathrm{ug}$ NAA with stigmatic fluid present & 2.66 & $4.64 \mathrm{a}$ \\
\hline Distilled water with stigmatic fluid removed & 2.72 & $2.65 \mathrm{C}$ \\
\hline $20 \mathrm{nmol}$ ACC with stigmatic fluid removed & 2.64 & $2.69 \mathrm{C}$ \\
\hline 20 ug NAA with stigmatic fluid removed & $\mathrm{ns}$ & $4.13 \mathrm{~b}$ \\
\hline F-test & $* *$ \\
\hline
\end{tabular}

${ }^{1}$ Means within columns not sharing the same letter are significantly different at $P=0.05$ (DMRT); ns $=$ not significant; ${ }^{* *} P<0.01$.

Table 3 Time to epinasty, drooping, venation and colour fading of Dendrobium 'Pompadour' flowers from which the stigmatic fluid was either removed or not prior to pollination.

\begin{tabular}{|l|c|c|c|c|}
\hline \multirow{2}{*}{\multicolumn{1}{|c|}{ Treatment }} & \multicolumn{4}{c|}{ Time (days) } \\
\cline { 2 - 5 } & Epinasty & Drooping & Venation & Colour Fading \\
\hline Non-pollinated flowers with stigmatic fluid & $9.0 \mathrm{a}$ & $12.3 \mathrm{a}$ & $12.1 \mathrm{a}$ & $13.8 \mathrm{a}$ \\
\hline Non-pollinated flowers with stigmatic fluid removed & $8.1 \mathrm{a}$ & $9.9 \mathrm{a}$ & $10.5 \mathrm{a}$ & $11.5 \mathrm{a}$ \\
\hline Pollinated flowers with of stigmatic fluid & $2.0 \mathrm{~b}$ & $3.6 \mathrm{~b}$ & $2.0 \mathrm{~b}$ & $4.0 \mathrm{~b}$ \\
\hline Pollinated flowers with stigmatic fluid removed & $2.4 \mathrm{~b}$ & $4.7 \mathrm{~b}$ & $4.0 \mathrm{~b}$ & $5.0 \mathrm{~b}$ \\
\hline F-test & $* *$ & $* *$ & $* *$ & $*$ \\
\hline
\end{tabular}

${ }^{1}$ Means within columns not sharing common letter are significantly different at $P=0.01$ based on DMRT; ${ }^{* *}=P=0.01$ and $\mathrm{n}=25$. 

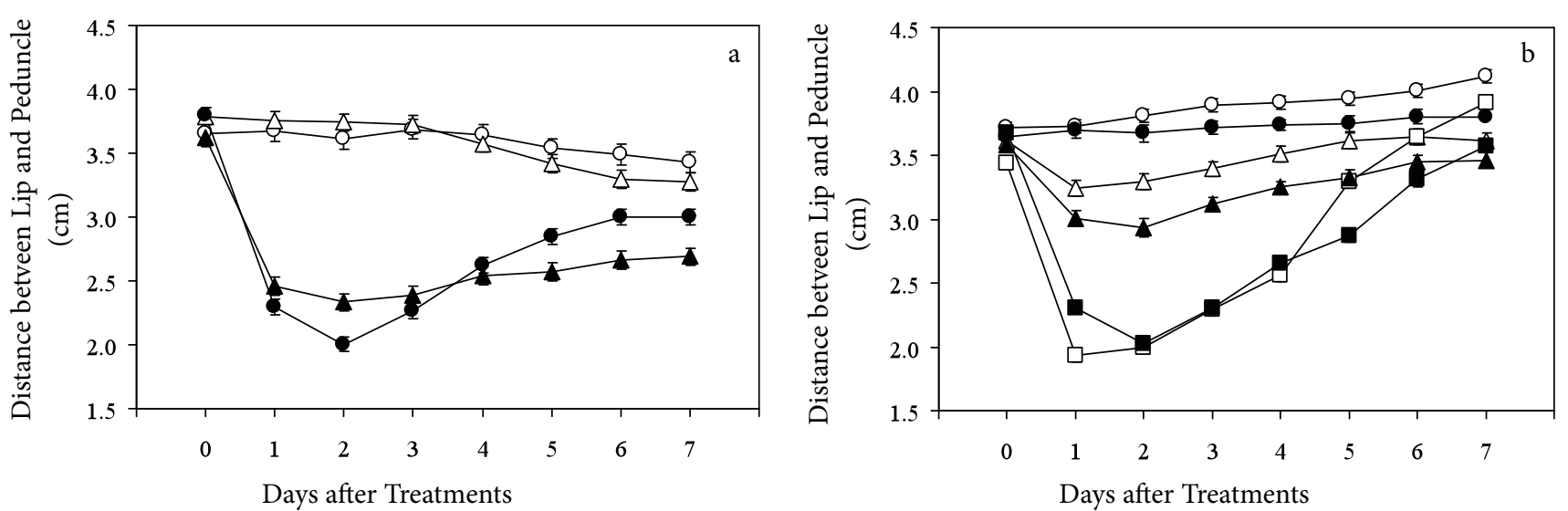

Fig. 3 (a) Distance between the lip and peduncle of non-pollinated $(\circ, \Delta)$ and pollinated $(\bullet, \boldsymbol{\Delta})$ flowers with $(\circ, \bullet)$ and without $(\Delta, \mathbf{\Delta})$ stigmatic fluid. (b) Distance between the lip and peduncle of non-pollinated flowers with $(\circ, \Delta, \square)$ and without $(\bullet, \boldsymbol{\Delta}, \boldsymbol{\square})$ stigmatic fluid and treated with either distilled water $(\circ, \bullet)$, NAA $(\square, \boldsymbol{\Xi})$ or ACC $(\Delta, \boldsymbol{\Delta})$. Values are means for 25 open florets \pm SE. Epinasty of the flower peduncle. Epinasty is shown as the change in distance between the lip and peduncle during day $0-2$. This change is due to an inward folding (called drooping) of the petals, including the lip.

was little difference between flowers with and without stigmatic fluid (Fig. 3b).

Symptoms of senescence included a change in petal colour, whereby the colour became less intense (colour fading) and the venation of the petals more visible. Pollination hastened these symptoms (Table 3). The presence or absence of stigmatic fluid had no effect (Table 3).

\section{Discussion}

Removal of stigmatic fluid did not significantly affect ethylene production. The absence of an increase in ethylene production indicates that removing stigmatic fluid did not physically damage the surface of the stigma. Removal of stigma fluid prior to pollination resulted in less marked epinasty and a smaller increase in the diameter of the ovary, but these effects were rather small.

In non-pollinated flowers treated with NAA or ACC, removal of stigmatic fluid did not affect the time to the increase ethylene production, but had a significant effect on the magnitude of the ethylene production, with NAA increasing and ACC decreasing ethylene production. It is unknown whether this has a physiological basis. It is suggested that the increase in ethylene production after pollination is due to the presence of ACC and auxin-like compounds. The present data indicate that if this is true the signals released from pollen do not need stigmatic fluid in order to induce an increase in ethylene production. Pollination-induced production of ethylene plays an important role in pollination-induced ovary growth in Dendrobium flowers, although an auxin is also required (Ketsa and Rugkong 2000a; Ketsa et al. 2001). Ovary growth of pollinated Dendrobium flowers was slightly but significantly less after pollination, if stigmatic fluid was removed. After placing pollinia on the surface of stigma with stigmatic fluid, the pollinia became swollen and firmly embedded in the stigmatic fluid. Substances from the pollen might have dissolved the stigmatic fluid. This could also lead to pollen-pistil interactions resulting in the signals required for ovary growth (Rosen 1975). Another possibility is that the stigmatic fluid stimulated pollen tube growth and therefore ovary growth (Martin 1973).

\section{Acknowledgements}

The research was financially supported by the Thailand Research Fund (TRF), the Commission on Higher Education (CHE), Ministry of Education and the Kasesart University Research and Development Institute (KURDI).

\section{REFERENCES}

Ketsa S, Luangsuwalai K (1996) The relationship between 1-aminocyclopropane-1-carboxylic acid content in pollinia, ethylene production and senescence of pollinated Dendrobium orchid flowers. Postharvest Biol Technol 8: 57-64.

Ketsa S, Rugkong A (1999) Senescence of Dendrobium 'Pompadour' flowers following pollination. J Hort Sci Biotechnol 74: 608-613.

Ketsa S, Rugkong A (2000a) Ethylene production, senescence and ethylene sensitivity of Dendrobium 'Pompadour' flowers. J Hort Sci Biotechnol 75: 149-53.

Ketsa S, Rugkong A (2000b) The role of ethylene in enhancing the initial ovary growth of Dendrobium 'Pompadour' following pollination. J Hort Sci Biotechnol 75: 451-454.

Ketsa S, Bunya-Atichart K, van Doorn WG (2001) Ethylene production and post-pollination development in Dendrobium flowers treated with foreign pollen. Austral J Plant Physiol 28: 409-415.

Konar RN, Linskens HF (1966) Physiology and biochemistry of the stigmatic fluid of Petunia hybrida. Planta 71: 372-87.

Lack AJ, Diaz A (1990) The pollination of Arum maculatum L. - a historical review and new observations. Watsonia 18: 333-342. 
Lovell PH, Lovell PJ, Nichols R (1987) The importance of the stig$\mathrm{ma}$ in flower senescence in petunia (Petunia hybrida). Ann Bot 60: 41-7.

Martin FW (1973) The nature of the stigmatic exudates and its role in pollen germination. In: Heslop-Harrison J (ed.). Pollen: Development and Physiology. Butterworth and Co (Publishers) Ltd., London, pp. 262-272.

O'Neill SD (1997) Pollination regulation of flower development. Ann Rev Plant Physiol Plant Mol Biol 48: 547-74.
O’Neill SD, Nadeau JA (1997) Postpollination flower development. Hort Rev 19: 1-58.

Porat R, Nadeau JA, Kirby JA, Sutter EG, O’Neill SD (1998) Characterization of the primary pollen signal in the postpollination syndrome of Phalaenopsis flowers. Plant Growth Regul 24: 109-117.

Rosen WG (1973) Pistil-pollen interactions in Lilium. In: Heslop-Harrison J (ed.). Pollen: Development and Physiology. Butterworth and Co (Publishers) Ltd., London, pp. 239-254. 